5. Bùi Quang Huy (2017), "Rối loạn lo âu", Nhà xuất bản $Y$ hoc, Hà Nôii.

6. Asadi-Pooya A.A. (2017), "Psychogenic nonepileptic seizures: a concise review",Neurol Sci; 38(6): 935-940.

7. Dayan J. and Olliac B. (2010), "From hysteria and shell shock to posttraumatic stress disorder: comments on psychoanalytic and neuropsychological approaches", ] Physiol Paris; 104(6): 296-302.

8. Rowiński T., Kowalska-Dąbrowska M., Strus W. et al. (2019), "Measurement of pathological personality traits according to the DSM-5: A Polish adaptation of the PID-5. Part II empirical results", Psychiatr Pol; 53(1): 23-48.

\title{
GÂY MÊ HỒI SỨC CHO BỆNH NHÂN Có KHOẢNG QT KÉO DÀI
}

\section{TÓM TẮT}

Khoảng QT kéo dài được đinh nghĩa là: QTc > 480 ms đối với nữ và > 470ms đối với nam, trong đó QTc là QT hiệu chỉnh được đo trên điện tâm đồ Khoảng QT kéo dài được chia thành 2 nhóm là hôi chứng QT kéo dài bẩm sinh và khoảng QT kéo dài mắc phải. Cả 2 loai đều có thể dấn đến rối loai nhip nguy hiểm là xoắn đỉnh, trong điều kiện thuận lợi. Nễu bểnh nhân mang rối loạn nhị này phải gây mể phẫu thuật thì nguy cơ xoắn đỉnh là rất cao. Hiện nay chưa có khuyến cáo cu thể về gây mê hồi sức cho bênh nhân có khoảng QT kéo dài. Trên cơ sở sinh lý bệnh của hội chứng, cơ chế tác dụng của các thuốc dùng trong gây mê, tác động của phương pháp vô cảm đến dẫn truyên cớ tim, đồng thời xem xét lại y văn, chúng tôi muốn phân tích và đưa ra một số khuyến cáo về việc sử dụng thuốc, các lưu ý trong giai đoan trước, trong, sau mổ nhằm bảo đảm an toàn tối đa cho những bệnh nhân mang rối loạn nhịp này.

Từ khóa: Gây mê hồi sức, hội chứng QT kéo dài, xoắn đỉnh

\section{SUMMARY \\ ANESTHESIA AND RESUSCITATION FOR PATIENTS WITH PROLONGATION OF QT INTERVAL}

Prolongation of QT interval is defined as: QTC > $480 \mathrm{~ms}$ for women and $>470 \mathrm{~ms}$ for men, where QTc is the corrected QT that is measured on the electrocardiogram. Long QT interval is divided into 2 groups: congenital long QT syndrome and acquired prolongation of QT interval. Both types can lead to the dangerous arrhythmia - torsades de pointes whenever favorable conditions. If a patient with this arrhythmia requires anesthesia for sugery, the risk of torsade de pointes is very high. There are currently no specific recommendations for general anesthesia for kind of patients. On the basis of the pathophysiology of the syndrome, the mechanism of action of drugs used in anesthesia, the impact of anesthesia methods on myocardial conduction, and also reviewing the

\section{${ }^{1}$ Trường Đại học Y Hà Nội}

Chiu trách nhiếm chính: Phạm Quang Minh

Email: quangminhvietduc@yahoo.com

Ngày nhận bài: 7.5.2021

Ngày phản biện khoa học: 24.6.2021

Ngày duyệt bài: 6.7.2021

\section{Phạm Quang Minh ${ }^{1}$}

literature, we would like to analyze and give some recommendations on the use of drugs, specifically notes in the peri-operation to ensure optimal safety for these kind of patients.

Keywords: Anesthesia, long QT syndrome, torsades de pointes

\section{I. ĐĂT VẤN ĐỀ}

Sau sự kiện cầu thủ người Đan Mạch bị đột quy khi đang thi đấu. Ngay lập tức, các bác sỹ chuyên khoa tim mach đã tìm hiểu nguyên nhân của tình trang này, một trong số các nguyên nhân là những rối loạn nhịp tim "nguy hiểm". Các rối loạn nhịp tim loại này thường không hoặc ít có biểu hiện lâm sàng, khó phát hiện trên điện tâm đồ nhưng có thể biến chuyển thành những rối loạn nhịp nghiêm trọng, gây tử vong trong một số điêu kiện thuận lợi. Với đặc thù chuyên ngành Gây mê hồi sức, chúng tổi muốn phân tích đến một khía cạnh khác, đó là khi những bệnh nhân mang rối loạn nhịp tim này cần gây mê để phẫu thuật thì cần chú ý những gì. Bởi lẽ thuốc mê, phương pháp gây mê và tác động của phẫu thuật là những yếu tố nguy cơ cao gây rối loạn nhịp nghiêm trọng trên những bệnh nhân đã có rổi loạn nhịp từ trước. Theo thống kê, các rối loạn nhịp "nguy hiểm" ngày càng tăng, ngoài rối loạn bẩm sinh thì rối loạn mắc phải chiếm tỷ lệ khổng nhỏ, việc chẩn đoán xác định đôi khi cần thăm dò rất chuyên sâu như xét nghiệm gen. Trong bài này chúng tôi tập trung vào phân tích một rối loạn nhịp tim khá thường gặp là khoảng QT kéo dài.

\section{II. ĐỊNH NGHĨA VÀ CHẨN ĐOÁN}

Độ dài khoảng QT hiệu chỉnh theo nhịp (QT corrected - QTc) được tính theo công thức Bazett: QTc $=$ QT/VRR. QTc thay đổi theo tuổi, giới tính. Khoảng QT kéo dài được định nghĩa là QTc > 470 ms đối với nam, > 480ms đối với nữ [1].

Các nhà lâm sàng chia rối loạn liên quan đến khoảng QT thành 2 loại: hội chứng QT kéo dài bẩm sinh (LQTS) và khoảng $\mathrm{QT}$ kéo dài mắc phải. Hơn 75\% bệnh nhân bị hội chứng QT kéo 
dài có liên quan đến đột biến gen, hiện nay đã xác định được 17 đột biến gen là nguyên nhân của hội chứng QT kéo dài, tập trung vào 3 typ: typ 1 chiếm $35 \%$, typ 2 chiếm $30 \%$, typ 3 chiếm $10 \%$ [2]. Khoảng QT kéo dài mắc phải có thể là hậu quả của thuốc, rối loạn điện giải hoặc bệnh lý. Cả hai loại đều có thể biến chuyển thành rối loạn nhịp nguy hiểm như xoắn đỉnh. Phần lớn bệnh nhân có khoảng QT kéo dài mắc phải không liên quan đến đột biến gen, chỉ có 5 $10 \%$ bệnh nhân bị QT kéo dài do thuốc có thể có đột biến gen. Ngược lại biểu hiện lâm sàng đầu tiên của hội chứng QT kéo dài bẩm sinh có thể xẩy ra trong hoàn cảnh bệnh nhân có khoảng QT kéo dài mắc phải.

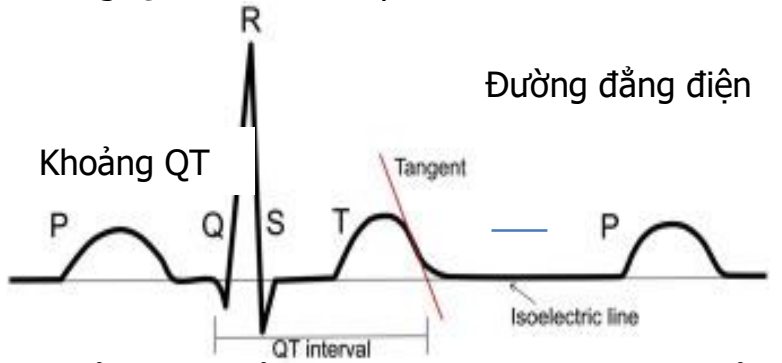

Biểu hiện kiểu hình của LQTS rất thay đổi, bệnh nhân có thể không có triệu chứng, chỉ có bẳng chứng về khoảng QT kéo dài trên điện tâm đồ 12 chuyển đạo khi nghỉ ngơi hoặc khi bị kích thích tái cực. Các hướng dẫn đồng thuận hiện tại của Hiệp hội Nhịp tim/Hiệp hội Nhịp tim Chẩu Âu nêu rõ rằng xét nghiệm di truyền nên được thực hiện nếu nghi ngờ LQTS bẩm sinh sau khi xem xét các đặc điểm lâm sàng, tiền sử gia đình và các đặc điểm điện tâm đồ. Việc định typ LQTS có ý nghĩa quan trọng trong việc tiên lượng, điều trị và dự phòng biến chứng [3].

- Typ 1: thường xuất hiện triệu chứng tim mạch khi gắng sức

- Typ 2: Ioạn nhịp thường khởi phát bởi tiếng động hoặc giật mình

- Typ 3: có thể đột tử ngay cả khi nghỉ ngơi hoặc trong khi ngủ

Ngoài một số bệnh lý tim mạch, rối loạn điện giải gây lên khoảng QT kéo dài mắc phải thì một số thuốc dưới đây có thể có thể là nguyên nhân. Các thuốc này được phân theo các nhóm như sau: Thuốc chống loạn nhịp nhóm IA, III; Thuốc kháng Histamin; Thuốc kháng sinh nhóm Macrolid, nhóm Quinolone; Thuốc điều trị rối loạn tâm thần; thuốc nhóm Opioid như Methadone...

Đứng trước một bệnh nhân có khoảng QT kéo dài, nếu có biển chứng như nhịp chậm, rung thất, xoắn đỉnh... cần can thiệp điều trị ngay.
Sau đó, bác sỹ lâm sàng cần xác định và loại trừ các nguyên nhân gây lên khoảng QT kéo dài mắc phải, nếu nguyên nhân hết mà trên điện tâm đồ vẫn còn biểu hiện thì sẽ phải xác định typ bằng phân tích đột biến gen [4].

\section{MộT SỐ LƯU Ý KHI GÂY MÊ CHO BỆNH NHÂN CÓ QT KÉO DÀl}

Những thuốc làm khoảng QT kéo dài trên những bệnh nhân bình thường hay có hội chứng QT kéo dài bẩm sinh có thể dẫn đến xoắn đỉnh được tìm thấy chi tiết trên trang web www.torsades.org. Tuy nhiên, trong danh sách này không nhắc đến thuốc dùng trong gây mê thuốc có thể ảnh hưởng đến dần truyền cơ tim và gây ra rối loạn nhịp nguy hiểm cho bệnh nhân trước trong hay sau mố ngay cả khi bệnh nhân đã được điêu trị đầy đủ bằng thuốc chẹn Beta. Chính vì vậy qua bài báo này chúng tổi muốn phân tích chi tiết những thuốc nên dùng hay phải tránh trên những bệnh nhân có khoảng QT kéo dài phải phẫu thuật.

1. Giai đoạn trước mổ.Cần làm ECG lúc nghỉ để xác định chắc chắn bệnh nhân có khoảng QT kéo dài hay không. Bệnh nhân đang được điều trị bằng chẹn Beta cần tiếp tục duy trì cho đến sáng ngày phẫu thuật. Những bệnh nhân không dùng chẹn beta thì cũng không cần dùng vì một số bệnh nhân QT kéo dài có thể nhịp chậm. Các rối loạn điện giải cần phải sửa chữa nhất là hạ Kali máu, hạ Mg máu và hạ Calci máu vì nó làm chậm tái cực. Các thuốc nằm trong danh sách có thể gây xoắn đỉnh phải dừng hoặc giảm liều nếu không được phép dừng. Khi bệnh nhân đã được cấy máy tạo nhịp hoặc máy khử rung tự động cần được kiểm tra tình trạng máy.

Thuốc sự dụng trong tiền mê có thể dẫn tới khoảng QT kéo dài. Tuy nhiên sự lo lắng và đau có thể khởi phát loạn nhịp trên bệnh nhân có hội chứng QT kéo dài, vì vậy một số thuốc tiền mê vẫn được khuyến cáo sử dụng. Antropin gây kéo dài khoảng QT nên không được phép sử dụng. Midazolam không làm kéo dài khoảng QT nên ưu tiên sử dụng. Hơn nữa, Midazoalm làm giảm hoạt động giao cảm mặc dù không làm giảm đáp ứng huyết động khi đặt nội khí quản. Để khắc phục, Lidocain $1,5 \mathrm{mg} / \mathrm{kg}$ tiêm tĩnh mạch trước đặt nội khí quản có thể dự phòng được kéo dài khoảng QT trong lúc đặt nội khí quản [5]. Vì vậy việc phối hợp giữa Midazolam và Lidocain được khyến cáo. Droperidol ảnh hưởng đến dẩn truyền cơ tim, bị rút khỏi thị trường từ năm 2001, nhưng được tái cấp phép từ năm 2008, thuốc được sử dụng nhằm 2 mục đích an thần 
và chống nôn cho bệnh nhân có hội chứng QT kéo dài.

2. Khởi mê và duy trì mê. Giữ môi trường phòng mổ yên tĩnh tránh tiếng động mạnh vì bênh nhân LQTS typ 2 có thể khởi phát loạn nhịp do tiếng động. Duy trì nhiệt độ phòng mồ khoảng $37^{\circ}$ tránh hạ nhiệt độ vì nhiệt độ thấp có thể kéo dài khoảng QT.

Với yêu cầu giảm giải phóng catecholamin với điều kiện sử dụng đầy đủ an thần và giảm đau, nên việc sử dụng morphin hoặc fentanyl được khuyến cáo. Mắc dù ảnh hưởng của fentanyl trển khoảng QTc vấn còn tranh luận, nhưng hiện nay Morphin và Fentanyl vẫn được sử dụng cho bệnh nhân có hội chứng QT kéo dài mà không có tác dụng phụ. Các thuốc cùng nhóm khác như Alfentanil không làm kéo dài tái cực và được phép sử dụng nhưng Sufentanil lại chống chỉ định.

Các thuốc mê bốc hơi (Halothane, Enflurane, Isoflurane, Servoflurane và Desflurane) gây kéo dài khoảng QT, ở các mức độ khác nhau. Servoflurane gây loạn nhịp ở trẻ em có hội chứng QT kéo dài bẩm sinh. Sự khác biệt về lâm sàng không rõ ràng nhưng theo khuyến cáo thì thuốc này nên tránh [6].

Ảnh hưởng của Propofol lên khoảng $\mathrm{QT}$ vẫn còn bàn cãi, tuy nhiên thuốc này nhanh chóng đảo ngược sự kéo dài QTc do Sevoflurane gây ra ở bệnh nhân khỏe mạnh, đây chính là ưu điểm của Propofol. Đối với Ketamin, mặc dù được sử dụng như thuốc tiền mê ở trẻ em, nhưng không được khuyến cáo ở bệnh nhân LQTS bởi thuốc có kích thích giao cảm nội tại làm dễ dàng xuất hiện xoắn đỉnh. Etomidat khồng ảnh hưởng đến tái cực thất, tuy nhiên theo nhiều nghiên cứu thì Etomidat tăng khoảng QT nhiều hơn so với Propofol.

Thuốc giãn cơ được dùng rộng hiện nay cả trong việc đặt nội khí quản và trong phẫu thuật. Succinylcholin đã từng được sử dụng cho bệnh nhân QT kéo dài. Anh hưởng của thuốc trên khoảng QT có thể được phục hồi bởi Alfentanil, Alfentanil tốt hơn Esmolol trong dự phòng tăng khoảng QT gây ra bởi Succinylcholine trong lúc đặt nội khí quản. Tuy nhiên, thuốc này ngoài tác dụng gây kéo dài khoảng $\mathrm{QT}$, nó còn kích thích phế vị gây vô tâm thu sau khi máy tạo nhịp bị ức chế bởi run cơ. Hơn nữa, hiện nay đã có nhiêuu loại thuốc giãn cơ khác ưu điểm hơn, vì vậy succinylcholin nên tránh. Rocuronium, vecuronium, atracurium, and cisatracurium không làm kéo dài khoảng QT và có thể sử dụng được, pancuronium nên tránh vì nó gây liệt phó giao cảm và có thể dẫn đến rung thất ở một số ca lâm sàng đã được thông báo trên y văn [7].
Đối với những phẫu thuật có thể áp dụng phương pháp vô cảm là tê tủy sống hay tê ngoài màng cứng thì sao? Khi mức phong bế của tê tủy sống đến $T 10$ có thể gây tăng hoạt tính giao cảm của những sợi giao cảm không bị ức chế. Việc phối hợp giữa tê tủy sống và tê ngoài màng cứng tỏ ra có nhiều ưu điểm vượt trội do tính ổn định huyết động hơn so với làm một kỹ thuật. Các thuốc tê (bupivacain, ropivacain) không làm kéo dài có ý nghĩa khoảng QT cũng như ít ảnh hưởng đến hoặt động điện của cơ tim. Tuy nhiên khi huyết áp tự do gây tê vùng thì không nên dùng Ephedrin vì thuốc này kích thích giao cảm dễ khởi phát cớn xoắn đỉnh.

3. Thời điểm đặt và rút nội khí quản. Cả 2 thời điểm đăt và rút nôi khí quản đều khởi phát xoắn đỉnh trên bệnh nhân bị hội chứng QT kéo dài bẩm sinh vì vậy cần dùng thuốc giảm đau và thuốc ức chế beta đầy đủ trước mổi thời điểm này. Khuyến cáo manh về việc sử dung Lidocain để dự phòng loạn nhịp trước khi đặt ống và trước khi rút ống [5]. Trong khi thông khí với áp lực dương, bác sỹ gây mê cần tránh áp lực đỉnh quá cao và cần giảm tỷ lệ $\mathrm{I} / \mathrm{E}$ bởi lẽ nghiệm pháp Valsalva cũng gây kéo dài khoảng QT.

4. Giai đoạn sau mổ. Cần lưu bênh nhân ở lại ICU ít nhất 24h, tránh cách kích thích có thể khởi phát cớn xoắn đỉnh. Ngoài giảm đau đầy đủ, dùng lại thuốc chẹn beta thì việc dự phòng nôn và buồn nôn cũng rất quan trọng. Tuy nhiên không nên dùng nhóm setrones bởi nhóm này không những ức chế $5 \mathrm{HT} 3$ mà còn ức chế luôn cả kênh HERG làm kéo dài thời gian tái cực.

5. Xử lý khi bị xoắn đỉnh. Xoắn đỉnh có thể xuất hiện bất kể thời gian nào nhưng tần xuất thì không liên tục. Những bệnh nhân bị liên tục hoặc có rối loạn huyết động thì cần phải được chỉ định cây máy shock điện không đông bộ. Các thuốc khởi phát cơn cần phải được phát hiện và dừng ngay lập tức. $\mathrm{MgSO}_{4}$ là thuốc điều trị cắt cơn hoặc dự phòng xoắn đỉnh: liều bolus $30 \mathrm{mg} / \mathrm{kg}$, duy trì $2-4 \mathrm{mg} / \mathrm{kg}$ truyền tĩnh mach. Giữa các cơn xoắn đỉnh bệnh nhân có thể có nhịp chậm nên cần chỉ định cấy máy tạo nhịp hoặc thậm chí cây máy shock điện tự động để dự phòng. Cần cài máy tạo nhịp với tần số ít nhất là 90 lần/phút có thể cao đến 110 lần/phút nếu cần. Bệnh nhân có khoảng $\mathrm{QT}$ kéo dài mắc phải hoặc xoắn đỉnh, isoproterenol hoặc dobutamine có thể sử dụng để dư phòng nhị chậm. Tuy nhiên, những thuốc này lại chống chỉ định ở bệnh nhân LQTS bẩm sinh vì có thể làm QT kéo dài hơn và dễ khởi phát loạn nhịp hơn. Những bệnh nhân xoắn đỉnh tái phát cân phải bù 
Kali và duy trì nồng động trong huyết tương cao hơn mức bình thường $(4,5-5.5 \mathrm{mmol} / \mathrm{l})$ để rút ngắn khoảng QT. An thân sâu hơn có thể được chỉ định để làm giảm trương lực giao cảm, xa hơn nữa là giảm rối loạn nhịp thất [8].

\section{KẾT LUẬN}

Phần lớn bệnh nhân LQST bẩm sinh hay QT kéo dài mắc phải có thể không có dấu hiệu gì đặc biệt trong các giai đoạn gây mê hoặc can thiệp phẫu thuật. Tuy nhiên sự xuất hiện rối loạn nhịp nghiêm trọng, đặc biệt xoắn đỉnh không phải là không có. Hiện nay chưa có khuyến cáo chi tiết về gây mê hồi sức cho bệnh nhân có hội chứng QT kéo dài bẩm sinh. Sau khi nghiên cứu y văn chúng tôi muốn đưa ra một số điểm chính cần làm trong các giai đoạn của cuộc mổ, có thể là tốt nhất cho bệnh nhân có hội chứng nguy hiểm này.

\section{TÀI LIÊU THAM KHẢO}

1. Rautaharju P.M. et al. AHA/ACCF/HRS recommendations for the standardization and interpretation of the electrocardiogram: part IV: the ST segment, T and $U$ waves, and the QT interval: a scientific statement from the American
Heart Association Electrocardiography. J Am Coll Cardiol. 2009; 53: 982-991.

2. Ackerman M.J. et al. HRS/EHRA expert consensus statement on the state of genetic testing for the channelopathies and cardiomyopathies: this document was developed as a partnership between the Heart Rhythm Society (HRS) and the European Heart Rhythm Association (EHRA). Heart Rhythm. 2011; 8: 1308-1339

3. Giovanni Fazio et al. Drugs to be avoided in patients with long QT syndrome: Focus on the anaesthesiological management. World J Cardiol. 2013; 5(4): 87 - 93.

4. M. O'Hare et al. Perioperative management of patients with congenital or acquired disorders of the QT interval. British Journal of Anesthesia. 2018; 120(4): $629-644$

5. Owczuk R, Wujtewicz MA et al. The effect of intravenous lidocaine on QT changes during tracheal intubation. Anaesthesia. 2008;63:924-931

6. Karagöz AH, Basgul E, Celiker V, Aypar U. The effect of inhalational anaesthetics on QTC interval. Eur ] Anaesthesiol. 2005;22:171-174

7. Kies SJ, Pabelick CM, Hurley HA, White RD, Ackerman MJ. Anesthesia for patients with congenital long QT syndrome. Anesthesiology. 2005;102:204-210

8. Sorajja D. Et al. Optimal antiarrhythmic drug therapy for electrical storm. J Biomed Res. 2015; 29: 20-34.

\section{TÌM HIỂU MộT SỐ YẾU TỐ LIÊN QUAN ĐẾN KẾT QUẢ PHỤC HỒI CHỨC NĂNG NHẬN THỨC TRÊN BỆNH NHÂN CHẤN THƯƠNG SỌ NÃO}

\section{TÓM TẮT}

Suy giảm nhận thức do chấn thương sọ não có thể ảnh hưởng đến nhiều lĩnh vực bao gồm chú ý, ngôn ngữ, trí nhớ, nhận thức tri giác và chức năng điều hành. Muc tiêu: Tìm hiểu một số yếu tố liên quan đến kết quả phục hồi chức năng nhận thức trên người bênh chấn thương sọ não. Đối tượng và phương pháp nghiên cứu: Phương pháp nghiên cứu tiến cứu, so sánh kết quả trước và sau can thiệp trên 33 bệnh nhân bệnh nhân chấn thương sọ não trên 18 tuổi vào điều trị nội trú tại bệnh viện Phục hồi chức năng Hà Nội. Kết quả và kết luận: Bệnh nhân chấn thương sọ não chủ yếu là nam giới chiểm tỷ lệ $78,8 \%$, nữ giới chiếm 21,2\%, tỷ lệ nam/nữ là 3.71/1. Độ tuổi và giới tính không ảnh hưởng đến phục hồi chức năng nhận thức của bệnh nhân chấn thương sọ não $(p>0,05)$. Những bệnh nhân có thời gian mắc bệnh dưới 6 tháng và trển 6 tháng không ảnh hưởng đến PHCN nhận

\section{*Trường Đại học Y Hà Nội}

Chịu trách nhiệm chính: Phạm Văn Minh

Email: pvminhrehab@yahoo.com

Ngày nhận bài: 6.5.2021

Ngày phản biện khoa học: 25.6.2021

Ngày duyệt bài: 6.7.2021
Phạm Văn Minh*, Phan Thị Kiều Loan*

thức của bệnh nhân chấn thương sọ não ( $p>0,05)$.

Tư khóa: Yếu tố liên quan, Phục hồi chức năng nhận thức, Chấn thương sọ não

\section{SUMMARY \\ FINDING SOME FACTORS RELATED TO THE EFFECTIVENESS OF COGNITIVE \\ REHABILITATION FOR PATIENTS WITH TRAUMATIC BRAIN INJURY}

Cognitive impairment due to traumatic brain injury can affect many areas including attention, language, memory, perceptual cognition, and executive function. Objective: To find some factors related to the outcome of cognitive rehabilitation in patients with traumatic brain injury. Patients and methodology: Prospective research method, comparing results before and after treatment on 33 patients with traumatic brain injury over 18 years old admitted to inpatient treatment at Ha Noi Rehabilitation Hospital. Results and conclusions: Most of the traumatic brain injury patients were male, accounting for $78.8 \%$, female accounted for $21.2 \%$, male/female ratio was 3.71/1. Age and gender did not affect cognitive rehabilitation of traumatic brain injury patients $(p>0.05)$. Patients with disease duration less than 6 months and more than 6 months did not affect 